\title{
OPTIMIZATION OF ANTIMICROBIAL ACTIVITY OF SYNTHESIZED S-TRIAZINE DERIVATIVES
}

\author{
GA. Swami* and KG. Bothara
}

Department of Pharmaceutical Chemistry, Sinhgad College of Pharmacy, S.No. 44/1, Vadgaon (Bk.), Off Sinhgad Road, Pune, Maharashtra-411 041, India.

\begin{abstract}
The emergence of new infectious diseases, the resurgence of several infections that appeared to have been controlled and the increase in bacterial resistance have created the necessity for studies directed towards the development of new potential antimicrobials. A series of novel sTriazine has been synthesized and screened for antimicrobial activities. The compound R3 and R10 obtained optimum antibacterial activity against S. aureus; compound R5 obtained optimum antibacterial activity against Pseudomonas aeruginosa and compound R6 obtained optimum antibacterial activity against Bacillus substilis, S. aureus and moderate activity against $E$. coli and $P$. aeruginosa at $25 \mathrm{ug} / \mathrm{ml}$ concentration
\end{abstract}

Keywords: infectious diseases; s-Triazine; antimicrobial and antibacterial activities.

\section{INTRODUCTION}

According to the World Health Organisation (WHO), infectious and parasitic diseases account for two to five of the top ten causes of deaths in the world. The need for new antimicrobials has been recognised by the WHO, the European Centre for Disease Control and Prevention, as well as by the European Medicines Agency.

Microorganisms have existed on the earth for more than 3.8 billion years and exhibit the greatest genetic and metabolic diversities. It is believed that they compose about $50 \%$ of the living biomass. In order to survive, they have evolved mechanisms that enable them to respond to selective pressure exerted by various environments and competitive challenges. These microorganisms have responded by developing resistance mechanisms to fight off this offensive. Currently antimicrobial resistance among bacteria, viruses, parasites, and other diseasecausing organisms is a serious threat to infectious disease management globally

In order to appreciate the mechanisms of resistance, it is important to understand how antimicrobial agents act. Antimicrobial agents act selectively on vital microbial functions with minimal effects or without affecting host functions. Different antimicrobial agents act in different ways. The understanding of these mechanisms as well as the chemical nature of the antimicrobial agents is crucial in the understanding of the ways how resistance against them develops. However, the mechanism of action of antimicrobial agents can be categorized further based on the structure of the bacteria or the function that is affected by the agents either by inhibition of the cell wall synthesis or inhibition of ribosome function or inhibition of nucleic acid synthesis or inhibition of folate metabolism or inhibition of cell membrane function etc.

s-Triazine is a versatile lead molecule for potential bioactive compounds and its derivatives were reported to possess antimicrobial activity. The identification of lead molecules against multidrug-resistant bacteria ensuing the development of novel antimicrobial drugs is an vital task. s-Triazine derivatives are an important class of organic heterocycles because of their potential bioactivity. Antimicrobial drugs are the greatest contribution of the present century to therapeutics. Drug in this class differ from other in that they are design to inhibit/ kill the infecting organisms \& to have no/ minimal effect on recipient. s-Triazine are known to 
possess a wide range of pharmacological activities like antibacterial ${ }^{1}$, antifungal, anti$\mathrm{HIV}^{2}$, anticonvulsant, antiviral, anticancer ${ }^{3}$. Some of the new s-Triazine bases, reported as potential biologically active compounds.

\section{MATERIALS AND METHODS}

All the compounds are synthesized by using Microwave assisted organic synthesis (MAOS) technique ${ }^{4,5,6}$, which offers simple, clean, fast, efficient, and economic for the synthesis of a large number of organic molecules.

For analytical characterization pre-coated Thin-layer chromatography (TLC) plates were used to confirm purity. The chemical structures were confirmed by means of Fourier-transform infrared spectroscopy (FTIR), ${ }^{1} \mathrm{H}$ Nuclear magnetic resonance $\left({ }^{1} \mathrm{H}\right.$ NMR), ${ }^{13} \mathrm{C}$ Nuclear magnetic resonance $\left({ }^{13} \mathrm{C}\right.$ NMR $)$ and Mass spectroscopic of synthesized compounds. Melting points was carried out on calibrated digital apparatus.

All compounds were screened for antibacterial Bacillus substilis, Escherichia coli, Staphylococcus aureus and Pseudomonas aeruginosa activities by paper disc diffusion technique.

The entire compound produced by following standard synthetic methods in synthetic chemistry laboratory and analytical screening done on calibrated and validated equipments and/or instruments.

\section{General method of synthesis}

The synthesized compound R1-R4 was an equimolar mixture of urea and substituted aniline was gently mixed with excess of aqueous formaldehyde then irradiated inside a microwave oven till the completion of the reaction then extracted from methanol and excess of solvent was evaporated on rotoevaporator to give a solid product then the product recrystallized from methanol to give the respective products. Similarly, compound R5-R10 was an equimolar mixture of thiourea and substituted aniline was gently mixed with excess of aqueous formaldehyde then irradiated inside a microwave oven till the completion of the reaction then extracted from methanol and excess of solvent was evaporated on roto-evaporator to give a solid product then the product recrystallized from methanol to give the respective products. Progress of reaction was monitored with TLC on pre-coated $\mathrm{SiO} 2$ gel aluminium plates and visualized in UV chamber. The synthetic target compounds and its potential derivatives are tabulated in Table 1

Table 1

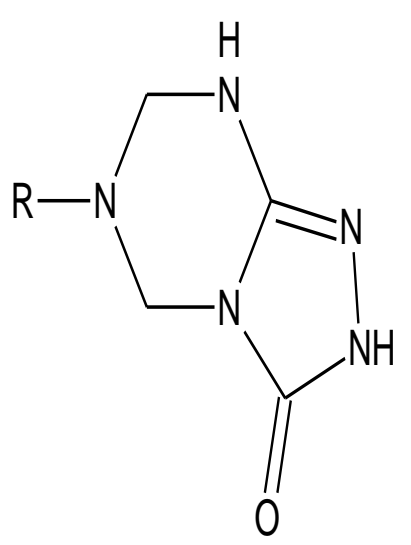

(R1-R4)

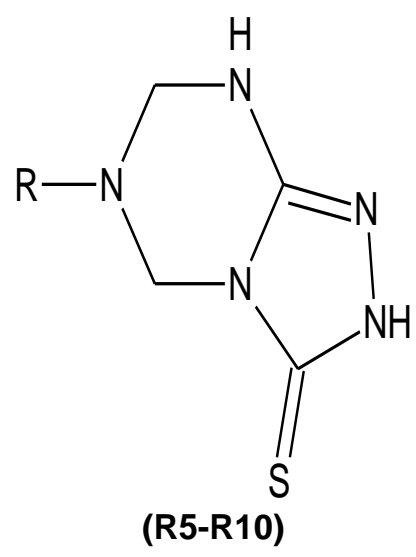

(R5-R10)

\author{
R1- 4CI C6H4 \\ R2- $40 \mathrm{CH} 3 \mathrm{C} 6 \mathrm{H} 4$ \\ R3- $2 \mathrm{Cl} \mathrm{C} 6 \mathrm{H} 4$ \\ R4- 2CH3 C6H4 \\ R5- $40 \mathrm{OH} 3 \mathrm{C} 6 \mathrm{H} 4$ \\ R6- 4NO2 $66 \mathrm{H} 4$ \\ R7- $2 \mathrm{Cl} 66 \mathrm{H} 4$ \\ R8- $2 \mathrm{CH} 3 \mathrm{C} 6 \mathrm{H} 4$ \\ R9- 20CH3 $\mathrm{C} 6 \mathrm{H} 4$ \\ R10- 2NO2 C6H4
}

\section{Measurements and Characterization techniques \\ The IR spectra of the compounds were} recorded on FT-IR spectrometer. ${ }^{1} \mathrm{H}$ and ${ }^{13} \mathrm{C}$ NMR spectra were recorded using a NMR spectrometer and for mass spectra were recorded using a Mass spectrometer. The purity of the compounds was checked by TLC on pre-coated $\mathrm{SiO}_{2}$ gel aluminium plates and visualized in UV chamber. IR, ${ }^{1} \mathrm{H}$ NMR, ${ }^{13} \mathrm{C}$ NMR and elemental analysis were consistent with the assigned structures. The s-Triazine derivatives synthesized by following standard synthetic methods in synthetic chemistry laboratory and analytical screening done on calibrated and validated equipments and/or instruments

\section{Biology investigation}

Antimicrobial screening ${ }^{7,8}$

The antibacterial activity of the synthesized compounds was tested against two Gram- 
positive bacteria (B. subtilis and $S$. aureus) and two Gram-negative bacteria ( $E$. coli and $P$. aeruginosa ) using nutrient agar medium.

\section{Paper disc diffusion technique}

Pre-sterile ready prepared plates of soyabean casein digest agar plate (Triple layer pack, Gamma irradiated) are used then the suspension of the microorganism poured into a petriplates. The paper was impregnated with the test compounds. Sterile paper disc made by punching whatman (No.41) paper were dipped separately in to the solutions containing synthesized drug $(\mu \mathrm{g} / \mathrm{ml}$ of DMSO) and standard drug amoxicillin $(\mu \mathrm{g} / \mathrm{ml}$ of DMSO) in aseptic condition with help of sterile forcep and were then placed on the surface of the pre-sterile ready prepared solidified media after which the plates were kept in refrigeration for 30 mins for the diffusion of the drug from the paper disc in to the culture media. After 30 mins the plates were incubated at $37^{\circ} \mathrm{C}$. The observed zone of inhibition is presented in Table $2 \mathrm{~A}$ and Table $2 \mathrm{~B}$. The result obtained was compared with standard drug Amoxicillin for antibacterial activity.

The compound R1-R10 were screened for their antibacterial activity in triplicate sets against their bacteria at different concentration of 1000,500 and $250 \mathrm{ug} / \mathrm{ml}$. The drugs which were found to be active in primary screening were further diluted to obtain 100, 50 and 25 $\mathrm{ug} / \mathrm{ml}$ concentration.

The highest dilution showing at least 99\% inhibition was taken as minimum inhibitory concentration (MIC). The test mixture should contain $10^{8}$ cells $/ \mathrm{ml}$. The standard drug used in this study was Amoxicillin.

\section{Minimum inhibitory concentration (MIC) ${ }^{9}$}

MIC of the synthesized compounds was determined by agar streak dilution method. A stock solution of the synthesized compound (100 $\mu \mathrm{g} \mathrm{mL-1)} \mathrm{in} \mathrm{dimethyl} \mathrm{formamide} \mathrm{was}$ prepared and graded quantities of the test compounds were incorporated in a specified quantity of Pre-sterile ready prepared plates.

Suspension of the microorganism was prepared to contain approximately $10^{5} \mathrm{cfu} / \mathrm{mL}$ and applied to plates with serially diluted compounds in dimethyl formamide to be tested and incubated at $37^{\circ} \mathrm{C}$ for $24 \mathrm{~h}$ for bacteria. The MIC was considered to be the lowest concentration of the test substance exhibiting no visible growth of bacteria on the plate. All the result of MIC value was summarized in Table $2 \mathrm{~A}$ and Table $2 \mathrm{~B}$.

Table 2A: Results of in vitro antimicrobial activity of the compounds (R1-R10)

\begin{tabular}{|c|c|c|c|c|c|c|c|c|c|c|c|c|}
\hline \multirow{4}{*}{ Compound } & \multicolumn{12}{|c|}{ Minimum Inhibitory Concentration (MIC) in ug/ml } \\
\hline & \multicolumn{6}{|c|}{ Gram-positive organisms } & \multicolumn{6}{|c|}{ Gram-negative organisms } \\
\hline & \multicolumn{3}{|c|}{ B. subtilis } & \multicolumn{3}{|c|}{ S. aureus } & \multicolumn{3}{|c|}{ E-Coil } & \multicolumn{3}{|c|}{ P.areginosa } \\
\hline & $\begin{array}{c}100 \\
0\end{array}$ & 500 & 250 & $\begin{array}{c}100 \\
0\end{array}$ & 500 & 250 & $\begin{array}{c}100 \\
0\end{array}$ & 500 & 250 & $\begin{array}{c}100 \\
0\end{array}$ & 500 & 250 \\
\hline R1 & +++ & +++ & +++ & +++ & +++ & +++ & +++ & +++ & +++ & +++ & +++ & +++ \\
\hline $\mathrm{R} 2$ & +++ & +++ & +++ & +++ & +++ & +++ & +++ & +++ & +++ & +++ & +++ & +++ \\
\hline R3 & +++ & +++ & +++ & +++ & +++ & +++ & +++ & +++ & +++ & +++ & +++ & +++ \\
\hline R4 & +++ & +++ & +++ & +++ & +++ & +++ & +++ & +++ & +++ & +++ & +++ & +++ \\
\hline R5 & +++ & +++ & +++ & +++ & +++ & +++ & +++ & +++ & +++ & +++ & +++ & +++ \\
\hline R6 & +++ & +++ & +++ & +++ & +++ & +++ & +++ & +++ & +++ & +++ & +++ & +++ \\
\hline R7 & +++ & +++ & +++ & +++ & +++ & +++ & +++ & +++ & +++ & +++ & +++ & +++ \\
\hline R8 & +++ & +++ & +++ & +++ & +++ & +++ & +++ & +++ & +++ & +++ & +++ & +++ \\
\hline $\mathrm{R9}$ & +++ & +++ & +++ & +++ & +++ & +++ & +++ & +++ & +++ & +++ & +++ & +++ \\
\hline R10 & +++ & +++ & +++ & +++ & +++ & +++ & +++ & +++ & +++ & +++ & +++ & +++ \\
\hline $\begin{array}{l}\text { Control } \\
\text { (DMSO) }\end{array}$ & - & - & - & - & - & - & - & - & - & - & - & - \\
\hline Standard & +++ & +++ & +++ & +++ & +++ & +++ & +++ & +++ & +++ & +++ & +++ & +++ \\
\hline
\end{tabular}

Table 2B: Results of in vitro antimicrobial activity of the compounds (R1-R10)

\begin{tabular}{|c|c|c|c|c|c|c|c|c|c|c|c|c|}
\hline \multirow{4}{*}{ Compound } & \multicolumn{12}{|c|}{ Minimum Inhibitory Concentration (MIC) in ug/ml } \\
\hline & \multicolumn{6}{|c|}{ Gram-positive organisms } & \multicolumn{6}{|c|}{ Gram-negative organisms } \\
\hline & \multicolumn{3}{|c|}{ B. subtilis } & \multicolumn{3}{|c|}{ S. aureus } & \multicolumn{3}{|c|}{ E-Coil } & \multicolumn{3}{|c|}{ P.areginosa } \\
\hline & 100 & 50 & 25 & 100 & 50 & 25 & 100 & 50 & 25 & 100 & 50 & 25 \\
\hline R1 & +++ & ++ & - & +++ & +++ & + & ++ & + & + & + & - & - \\
\hline $\mathrm{R} 2$ & +++ & +++ & + & + & - & - & +++ & +++ & ++ & ++ & ++ & + \\
\hline R3 & ++ & - & - & +++ & +++ & +++ & + & - & - & + & + & - \\
\hline $\mathrm{R} 4$ & +++ & +++ & + & + & - & - & ++ & + & - & +++ & & + \\
\hline R5 & +++ & +++ & ++ & + & + & - & - & - & - & +++ & +++ & +++ \\
\hline $\mathrm{R} 6$ & +++ & +++ & +++ & +++ & +++ & +++ & +++ & +++ & ++ & +++ & ++ & ++ \\
\hline R7 & ++ & + & ++ & ++ & + & - & +++ & +++ & ++ & ++ & + & + \\
\hline R8 & + & ++ & ++ & + & + & + & +++ & +++ & - & ++ & - & - \\
\hline $\mathrm{R9}$ & +++ & +++ & ++ & ++ & - & $=$ & ++ & + & + & + & + & ++ \\
\hline R10 & ++ & ++ & + & +++ & +++ & +++ & ++ & + & - & ++ & + & + \\
\hline
\end{tabular}




\section{\begin{tabular}{|c|c|c|c|c|c|c|c|c|c|c|c|c|} 
Control (DMSO) & - & - & - & - & - & - & - & - & - & - & - & - \\
\hline
\end{tabular}}

\section{Synthesis}

The synthetic target compounds and its potential derivatives are tabulated in Table 1. The structures of the compounds were characterized by $\mathrm{IR},{ }^{1} \mathrm{H} \mathrm{NMR},{ }^{3} \mathrm{C} N \mathrm{NMR}$ and Mass analysis.

\section{Antimicrobial evaluation}

For this reason all the synthesized compounds were evaluated for in vitroantimicrobial activities against Gram positive and negative bacteria.

From the results we can see that the synthesized compounds R3 and R10 obtained most potent antibacterial activity against $S$. aureus; compound R5 obtained optimum antibacterial activity against Pseudomonas aeruginosa and compound R6 obtained optimum antibacterial activity against Bacillus substilis, S. aureus and moderate activity against $E$. coli and $P$. aeruginosa at $25 \mathrm{ug} / \mathrm{ml}$ concentration.

From the results we can see that the synthesized compounds were moderately active against tested.

\section{CONCLUSION}

The antimicrobial activity of the synthesized compounds may be due to the presence of the versatile pharmacophore which might increase the lipophilic character of the molecules, which facilitate the crossing through the biological membrane of the microorganism and thereby inhibit their growth. For this reason, we can see that compound R3 and R10 was found to exhibit the most potent antimicrobial activity against $S$. aureus whereas compound R5 obtained optimum antibacterial activity against Pseudomonas aeruginosa and compound R6 obtained optimum antibacterial activity against Bacillus substilis, $\mathrm{S}$. aureus and moderate activity against $E$. coli and $P$. aeruginosa at $25 \mathrm{ug} / \mathrm{ml}$ concentration for antimicrobial evaluation.
1. Cervantes $\mathrm{HI}$, Alvarez JA, Munoz JM, Arreguin V, Mosqueda JL and Macias AE. Antimicrobial activity of copper against organisms in aqueous solution: a case for copper-based water pipelines in hospitals. American Journal of Infection Control. 2013;41(12):e115-e118.

2. Vzorov AN, Bhattacharyya D, Marzilli LG and Compans RW. Prevention of HIV-1 infection by platinum sTriazines. Antiviral Research. 2005;65(2):57-67.

3. Abdi K, Hadadzadeh $H$, Salimi $M$, Simpson $J$ and Khalaji AD. A mononuclear copper(II) complex based on the polypyridyl ligand 2,4,6tris(2-pyridyl)-1,3,5-s-Triazine (tptz), [Cu(tptz)2]2+: X-ray crystal structure, DNA binding and in vitro cell cytotoxicity. Polyhedron. 2012;44(1):101-112.

4. Gabriel C, Gabriel S, Grant E, Dalstead BSJ and Mingos DMP. Chem Soc Rev. 1998;27: 213-224.

5. Gedye RN, Wei JB and Can. J Chem. 1998;76:525-532.

6. Langa F, De la Cruz, De la Hoz, DiazOrtiz, Diez-Barra E. contemp Org Synth. 1997;4: 373-386.

7. Bauer AW, Perry DM and WMM. Kirby. Single disc antibiotic sensitivity testing of Staphylococci. AMA. Arch Intern Med. 1959;104:208-216.

8. Clinical Laboratory Standards Institute. 2006. Performance standards for antimicrobial disk susceptibility tests; Approved standard-9th ed. CLSI document M2-A9. 26:1. Clinical Laboratory Standards Institute, Wayne. PA.

9. Winn JrW. Konemann's color atlas and diagnostic text of microbiology. Lippencott Williams and Wilkins Publishers, Philadelphia, PA. 2006; 6th ed, 945-1021. 